\title{
Productivity Analysis of Tree-Length Harvesting using Farm Tractor in a Nordmann Fir Stand in Turkey* Sadık Çağlar** (iD
}

\author{
Kastamonu University, Faculty of Forestry, 373150 Kastamonu, Turkey
}

\begin{abstract}
Because of the low investment costs, the winch equipped farm tractors usage is the most common logging technique for the primer transportation of wood-based forest products in Turkey. During the logging operations, farm tractors are commonly used for cable winching at a steep terrain while they are used for skidding operation on relatively flat terrain conditions in forest stands. The aim of this study was to evaluate the working conditions and determine the productivity of uphill winching using a farm tractor during tree length harvesting operation in a Nordmann fir stand (Abies nordmanniana). The study was conducted in Western Black Sea Region of Turkey. The average diameter and length of the forest products which were hauled from stump-site to landing areas were $17 \mathrm{~cm}$ and $28 \mathrm{~m}$, respectively. The winching distances were ranged from $10 \mathrm{~m}$ to $70 \mathrm{~m}$. Time analysis and field measurements related to independent variables (including winching distance, tree diameter, length and volume) were conducted while the farm tractor was winching the harvested forest products. For the farm tractor, the productivity was estimated and the cycle time prediction model was developed using the multiple regression method. It was found that the average hourly and daily productivity were $5.80 \mathrm{~m}^{3} /$ hour and $46.42 \mathrm{~m}^{3} /$ day for 8 hours, respectively. The most time consuming work element was winching $(49.2 \%)$, followed with delay time (20.1\%).
\end{abstract}

Keywords: Forest harvesting, Farm tractor, Winching, Productivity

\section{Introduction}

A harvesting system refers to the combination of tools, equipment and machines used to conduct forest harvesting operation. The individual component of the system can be changed without changing the harvesting method. There are three main harvesting methods including cut-to-length, tree-length, and whole-tree methods. In the cut-to-length (CTL) method, the trees are felled, delimbed and bucked in the stump site and logs are transported to the landing area. In the tree-length harvesting (TLH) method, the trees are felled, delimbed and topped in the stump area and tree-lengths are transported to the landing area. In the whole-tree harvesting (FTH) method, the trees are felled and transported to the landing area with the branches (Pulkki, 2019). The most common harvesting method in Turkey is the CTL method because of the steep terrain conditions, insufficient mechanization, and low standards of the forest roads.

There are two stages in the transportation of woodbased forest products from stump site to the mils. The primer transportation is to transport forest products from stump to landing areas on road side (Figure 1). The seconder transportation is to transport forest products from the landing areas to the forest depots or the mills (Aykut, 1985; Çağlar, 2016). Comparing these stages, the primer transportation is considered as the most dangerous, difficult, expensive and time consuming tasks especially on the difficult terrain conditions.
In many countries, small and fragmented forestland is quite common. Small forest owners seek for solutions that provides profit increase with small investments. Farm tractor is a common equipment used in small-scale harvesting operations (Spinelli and Magagnotti, 2012). In Turkey, the farm tractors are also mostly used harvesting equipment for the transportation of the forest products in various sizes such as logs, stems or wholetrees. Generally, farm tractors have been combined with the light scale winches and its drums to haul small diameter harvested trees (Çağlar, 2016). Thus, the farm tractors are mostly used for the primer transportation of the small volume forest products on gentle terrain.

In practice, mostly forest villagers and rarely forest contractors have been carried out timber harvesting in Turkey. The constitution, forestry laws and regulations dictate that all forest works should be conducted by forest villagers or their cooperatives which is near to harvesting site. Farm tractors are owned by forest villagers to be used for the utilizations of both agricultural and forestry. Especially, the modified farm tractors have been employed for the primer transportation of the harvested trees either by cable winching or skidding directly on skid trails. The farm tractors can skid logs downhill, up to $25 \%$ ground slope. The winch-attached farm tractors are used for uphill extraction of logs up to distance of $30 \mathrm{~m}$ to $50 \mathrm{~m}$ (Akay, 2005).

\footnotetext{
* This work has been partially presented in FETEC2019 Symposium

**Author: Tel: +90 5365667852 E-mail: scaglar@kastamonu.edu.tr 


\begin{tabular}{|c|c|c|c|}
\hline \multirow{3}{*}{$\begin{array}{l}\mathbf{S} \\
\mathbf{T} \\
\mathbf{A} \\
\mathbf{G} \\
\mathbf{E}\end{array}$} & \multicolumn{3}{|c|}{ TREE HARVESTING PROCESS } \\
\hline & \multirow[b]{2}{*}{ CUTTING } & \multicolumn{2}{|c|}{\begin{tabular}{|c|} 
TRANSPORT STAGE \\
\end{tabular}} \\
\hline & & $\begin{array}{l}\text { PRIMER } \\
\text { TRANSPORT }\end{array}$ & $\begin{array}{l}\text { SECONDER } \\
\text { TRANSPORT }\end{array}$ \\
\hline \multirow{6}{*}{$\begin{array}{c}\mathbf{A} \\
\mathbf{C} \\
\mathbf{T} \\
\mathbf{I} \\
\mathbf{V} \\
\mathbf{I} \\
\mathbf{T} \\
\mathbf{I} \\
\mathbf{E} \\
\mathbf{S}\end{array}$} & Cutting preparation & \multirow{3}{*}{\begin{tabular}{|l|} 
Preparation \\
Loading (fastening) \\
Extraction (skidding, \\
hauling) \\
Unloading (untie) \\
\end{tabular}} & \multirow{3}{*}{$\begin{array}{l}\text { Loading } \\
\text { Transportation on road } \\
\text { Unloading }\end{array}$} \\
\hline & Cutting-felling & & \\
\hline & $\begin{array}{l}\text { Delimbing } \\
\text { Topping }\end{array}$ & & \\
\hline & Measuring marking & \multirow{3}{*}{$\begin{array}{l}\text { Timber stacking } \\
\text { (temporarily stacking) }\end{array}$} & \multirow{3}{*}{ Storage } \\
\hline & Bucking & & \\
\hline & Debarking & & \\
\hline
\end{tabular}

Figure 1. Motor-manual tree harvesting in practice in Turkey (Karaman, 1997)

Despite the increasing popularity of industrial forest equipment, intermediate harvesting technology is still widespread wherever non-industrial private forestry is prevalent, in both the developing and the developed countries (Magagnotti et al., 2016). Because of the high investment and purchase price of sophisticated forest machines (such as harvester, feller-buncher, skidder), modified farm tractor is a common solution for the transportation of forest products on gentle terrain condition. In recent decades, the usage of winchequipped farm tractors has increased in the primary transportation in Turkey.

The productivity of the farm tractors depends on various factors including machine and attached equipment's type, conditions of the forest ground and stand, weather conditions, and the experience and skills of the operators (Gullberg, 1995; Öztürk, 2010a; Çağlar 2016). Assessment of these factors and developing their corresponding time models can assist forest managers to select the suitable method for extracting forest products, and to efficiently manage the process of harvesting operations. One of the common methods implemented to evaluate the performance of a harvesting system are time study and productivity analysis (Ghaffariyan, 2020).

The aims of this study were: 1) measuring the time consumption of tree-length winching by a farm-tractor in a Nordmann fir stand located in the city of Kastamonu in Turkey while considering the effects of independent variables (i.e. winching distance, tree diameter, length and volume), 2) determination of the productivity, and 3) developing a cycle time prediction model for the farm tractor winching operation.

\section{Material and Methods \\ 2.1. Study Area}

The experimental site is located in Adalar Forestry District (FD) in Kastamonu Regional Directorate of Forestry (RDF) in north west of Turkey (Figure 2). The study was carried out in a forest stand (Compartment no: 58) that is actively managed for timber production and represents typical local conditions in the Adalar Forest District. In the stand, the primary forest tree species was Fir (Abies nordmanniana) mixed with Scotch pine (Pinus sylvestris). The stand type was symbolized as GÇsD which means uneven-aged forest mixed with fir and Scotch pine. The selected forest stand is located at latitude of $41^{\circ} 34^{\prime} 44.16^{\prime \prime} \mathrm{N}$ and longitude of $033^{\circ} 25^{\prime} 29.53^{\prime \prime} \mathrm{E}$.

This field study, simulating different winching operations under the experimental conditions, was conducted in April 2018. The working condition were favorable with a mean day temperature of $15^{\circ} \mathrm{C}$ and dry terrain conditions. The average ground slope of the study area was measured as $45 \%$ and the average elevation of the area was $1350 \mathrm{~m}$. The forest road density was 16 $\mathrm{m} /$ ha while forest road spacing was $625 \mathrm{~m}$ at study area. At the research area, the ground flora percentage was $15 \%$ on cable lane.
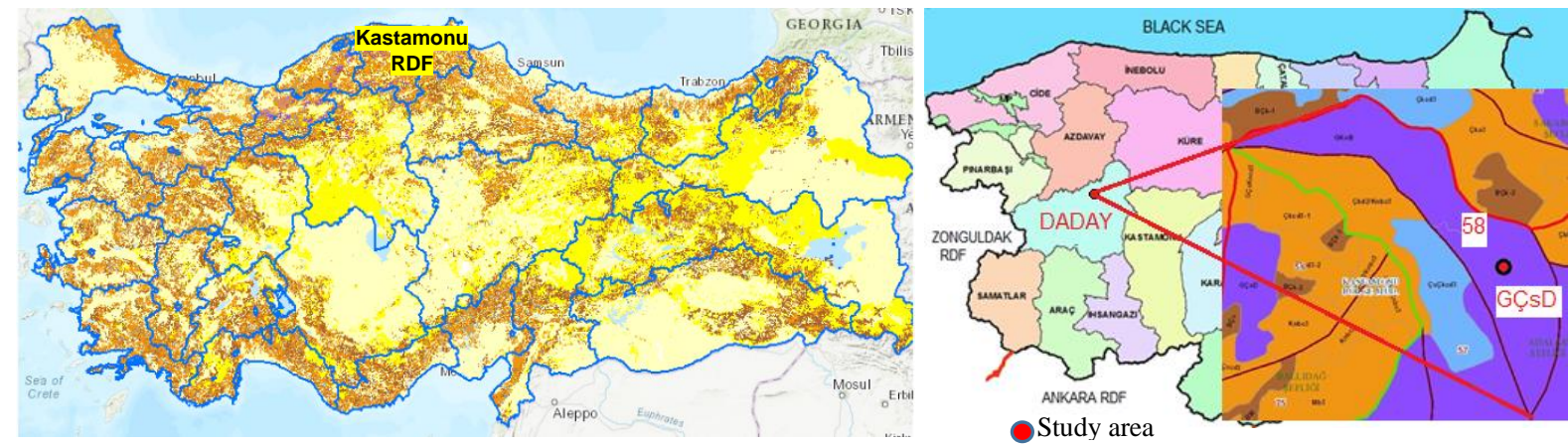

Figure 2. Map of the study area in Kastamonu RDF 


\subsection{Data Collection}

A single drum hydraulic winch-equipped Branson 6530 farm tractor was used for the extraction of motormanually felled tree-length products. This type of farm tractor was selected as the representative extraction machine in the region. The diameter and length of the steel cable on this winch was $12 \mathrm{~mm}$ and $100 \mathrm{~m}$, respectively. Technical specifications of the farm tractor were given in Table 1.

Tree felling and processing was carried out with the chainsaw which is the most popular method in Turkey. After the tree felling and procession, a time-motion study was carried out to estimate the time consumption and production rate of the farm tractor during the extraction of the tree-length products and to identify the factors that affect these variables in the study area.
There were two male forest workers conducting the winching operations within a working day. They were considered as the representatives of the forestry workers in the region. One of the workers was a choker setter attaching (choking) and untying the load while the other was machine operator (Figure 3). The ages of the machine operator and choker setter was 40 and 50 years old, respectively. Both of them were experienced (i.e. more than 10 years) cable extraction works under the condition of regional logging operations. Time measurements were conducted by using a hand chronometer. A time study form was developed to record time consumptions. Each work element in a cycle was recorded with the help of the data recording forms which specially designed for winching operation. In the field, the extraction distances were measured with a steel tape measure.

Table 1. Technical specifications of the Branson 6530 farm tractor

\begin{tabular}{ll}
\hline Machine power & $65 \mathrm{HP}(48,5 \mathrm{~kW})$ \\
Engine type & B3.3 NA \\
Number of cylinder / its capacity & $4 / 2347 \mathrm{~cm}^{3}$ \\
Transmission type & Synchronized \\
Fuel capacity & $90.9 \mathrm{lt}$ \\
3 Point hitch type & Cat II \\
Number of gears: forward /backward & $24 / 24$ \\
Cable diameter & $12 \mathrm{~mm}$ \\
Cable length & $100 \mathrm{~m}$ \\
Tire size: front /rear & $11.2-20 / 14.9-30$ \\
A: Overall length & $3647.45 \mathrm{~mm}$ \\
B: Width outside frame & $1880.62 \mathrm{~mm}$ \\
C: Height to top of cab & $2539.9 \mathrm{~mm}$ \\
D: Wheelbase & $2032.02 \mathrm{~mm}$ \\
\hline
\end{tabular}

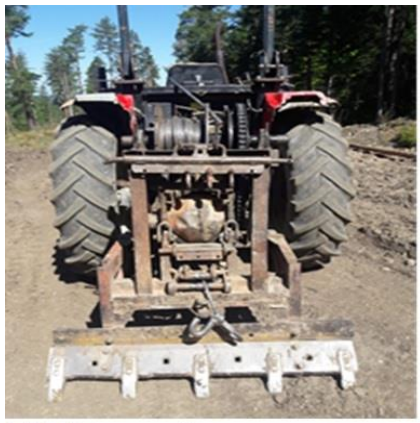

T1: Preparation-empty turn

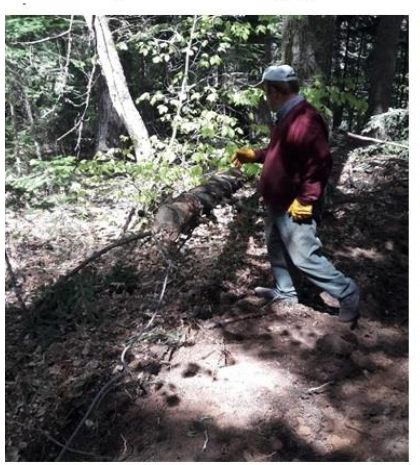

T4: Winching/walking back to the forest road

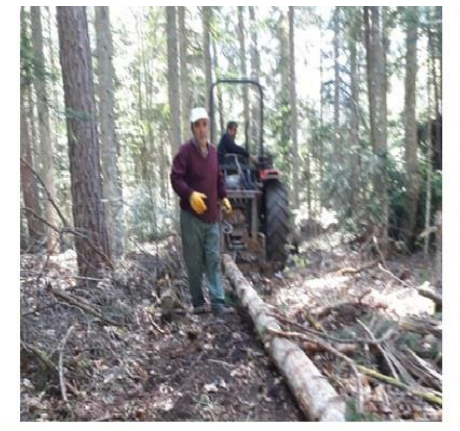

T2: Pulling out time of the cable
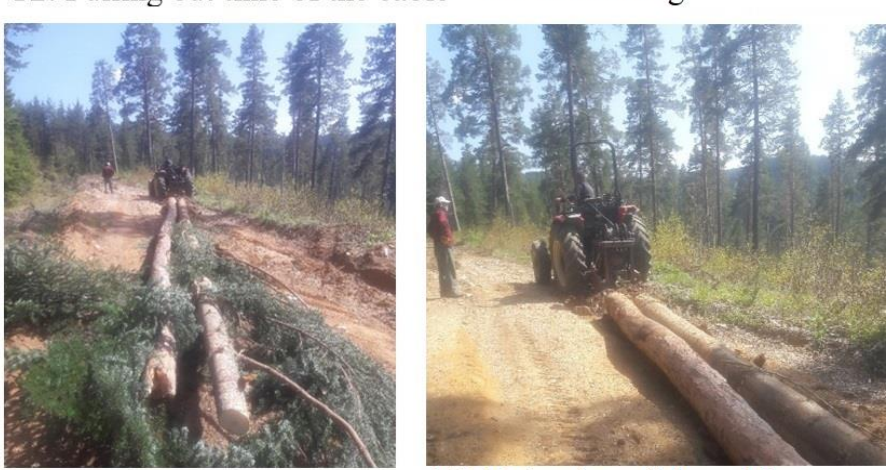

T5: Releasing of the cable

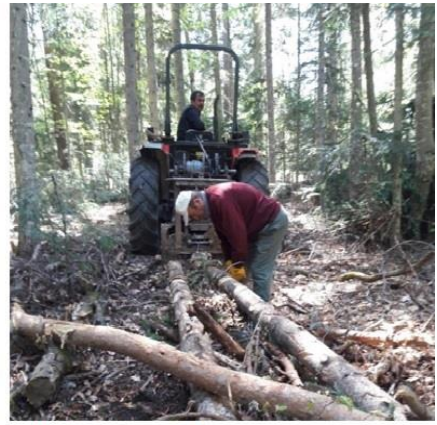

T3: Connecting

Figure 3 . Work elements in a cycle during the winching at the harvesting site 


\subsection{Method}

Time consumptions were studied by repetition time measurement method. The duration of time between starting and ending of the winching operation was considered as winching cycle time. The time measurement was recorded when the farm tractor moved along the forest road/skid trails to haul the felled trees (Figure 3). The time measurement was finished when the worker unhooked the products on the landing area. The time was recorded as second (s) on the study forms. The winching time (i.e. a cycle time) was measured for all the tree-length products in different diameters. The supplementary times (such as refueling, repairmaintenance, smoking and resting time of workers) were not included to the winching time of farm tractor.

A cycle was defined as the time needed to extract a single load to the landing area. Each winching cycle was measured separately with the delays (Koutsianitis and Tsioras, 2017). The repetitive time measurement technique was used during the winching operation of farm tractors. Each completed work element in a cycle was recorded separately. The cycle time (dependent variable) consisted of five main work elements during the winching operations (Figure 3). These elements were described as below;

T1: Preparation/empty turn time of tractor on the forest $\mathrm{road} / \mathrm{skid}$ trail,

T2: Pulling out time of the cable to the load by worker,

T3: Connecting time of the load to the cable at the at the corridor,

T4: Winching/walking back time to the forest road during the load was being winched,

T5: Releasing time of the chokers when the load reached to the forest road,

DT: Delay times due to obstacle recovery on ground, reattachment of the unhooked cable and other reasons.

CT: Cycle time is the sum of the work element times with the delay time.

NCT: Net Cycle time: It was obtained by subtracting the delay time from the cycle time (CT- DT).

For the estimation of productivity (in $\mathrm{m}^{3}$ per hour), the delay time was considered. In addition to the time measurements, dimensions of the extracted forest products (log diameter, log length) were also measured. The measured independent variables which effect the time consumption during the winching operation were; winching distance (WD) and diameter (d), length (L) and volume $(\mathrm{V})$ of the winched tree-length products in each cycle.

The volume of skidded products was estimated by measuring tree length and diameter at mid-length over bark. Huber's formula was commonly preferred formula in the technical application (Eker et al., 2011; Gülci et al., 2017) to calculated the volume in cubic meters $\left(\mathrm{m}^{3}\right)$ :

$V=\pi / 4 *(d)^{2} * L$

where $\mathrm{V}=$ Volume $\left(\mathrm{m}^{3}\right), \mathrm{d}=$ diameter at mid-length of $\log$ (m), $\mathrm{L}=$ length of $\log (\mathrm{m})$

Production rates were calculated using following equation (Koutsianitis and Tsioras, 2017):

$P=(V / T)^{*} 60$

where $\mathrm{P}=$ productivity ( $\mathrm{m}^{3} /$ hour $), \mathrm{V}=$ the volume of logs $\left(\mathrm{m}^{3}\right), \mathrm{T}=$ cycle time with delay time (minutes)

The dependent variables (work cycle elements and a cycle time) were brought into relation with the independent variables as (yii) $=\mathrm{f}$ (xii). Analysis of correlation and regression were conducted to find the «time consumption prediction model» by using SPSS IBM software version 24. Two tailed Pearson multiple correlation analysis was applied to determine the direction and intensity level of the relationship between the dependent and independent variables.

Multiple regression analysis was used to estimate the significance of relationship between the winching cycle time and the independents variables, including winching distance and extracted product sizes (Magagnotti et al., 2016) such as log diameter, log length and volume. Stepwise regression analysis was also used to find the prediction model of the winching cycle time. Results of the statistical analyses were considered significant if $\mathrm{p}<0.05$ (Koutsianitis and Tsioras, 2017).

\section{Results}

\subsection{Time Consumption and Productivity}

In this study, the harvesting system was the treelength system in which trees were felled, topped and delimbed at the stump in forest stand. Then, the treelengths were hauled to the landing area where their diameters and lengths were measured. A field based research was performed during the winching operation of the tree-length products by using Bronson 6530 farm tractor.

The direction of the extraction was from downhill to uphill at harvesting sites. The average ground slope of the harvesting area was $35 \%$. The mean longitudinal slope of skid trails was determined as $13 \%$ at the study site. The mean extraction distance was $37.14 \pm 15.51 \mathrm{~m}$. The average diameter and lengths of the extracted trees were $16.71 \mathrm{~cm}$ and $27.71 \mathrm{~m}$, respectively. The mean volume of extracted load was calculated as $0.618 \mathrm{~m}^{3}$ in a winching cycle (Table 2). 
Table 2. Descriptive statistics of the independent variables

\begin{tabular}{|c|c|c|c|c|}
\hline & \multicolumn{4}{|c|}{ Winching distance $(\mathrm{m})$ Diameter $(\mathrm{cm})$ Length $(\mathrm{m})$ Volume $\left(\mathrm{m}^{3}\right)$} \\
\hline Average \pm SI & $37.14 \pm 15.51$ & $16.71 \pm 2.72$ & $27.71 \pm 4.63$ & $0.618 \pm 0.206$ \\
\hline Range & $10.0-70.0$ & $12.0-21.0$ & $21.0-38.0$ & $0.305-1.040$ \\
\hline
\end{tabular}

During the time study, a total of 35 winching operations were examined to determine the average winching cycle time of the farm tractor. The average values \pm standard deviation (SD) of the work times were given in Table 3. It was found that the average cycle time (CT) of the winching operation was calculated as $6.39 \pm 3.39$ minutes. The average winching distance and winching time was $37.14 \mathrm{~m}(10-70 \mathrm{~m})$ and 0.81 minutes (for 10 meters), respectively.

In this study, the distribution of work elements in a cycle time was determined as $\mathrm{T} 4>\mathrm{DT}>\mathrm{T} 2>\mathrm{T} 1>\mathrm{T} 3>\mathrm{T} 5$ for the winching operation of tree length hauling with a farm tractor. The averages percentages (\%) of the time spent on work elements in a work cycle was given Figure 4. Within the work elements, the winching time $(\mathrm{T} 4=$ $3.17 \mathrm{~min}$ ) was the one with the highest time consumption rate $(49.2 \%)$ during the winching operation of the farm tractor. In addition to work elements, a cycle time included some kinds of delay times in the 24 cycles during winching operations. It was found that the second work with the highest rate was the delay time (20.1\%). The average delay time was calculated as $1.91 \mathrm{~min} / \mathrm{cycle}$ considering the 24 work cycles with delays. In this present study, observed delay times were classified into three groups during the winching operations. These were; (1) time consumption for obstacle-recovery, (2) reconnecting the untied cable/chokers and (3) other reasons (worker related such as smoking etc). The third most time consuming work element in a cycle was the pull-out time of the cable (14.3\%), followed by the preparation/empty turn time $(12.0 \%)$, the connecting time $(2.4 \%)$, and releasing time $(2.2 \%)$.

The productivity of farm tractor was calculated for the daily work shift of 8 hours. The productivity values of farm tractors at given conditions are given in Table 4 . The average hourly and daily productivities were calculated as $5.80 \mathrm{~m}^{3} /$ hour and $46.42 \mathrm{~m}^{3} /$ day for 8 hours, respectively.

Table 3. Time study results for the cycle time and working elements

\begin{tabular}{|c|c|c|c|c|c|c|c|c|}
\hline $\begin{array}{l}\text { Descriptive } \\
\text { statistics } \\
\text { (SD: Standard } \\
\text { deviation) }\end{array}$ & 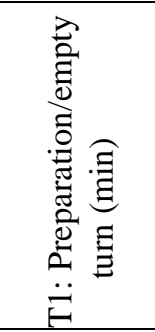 & 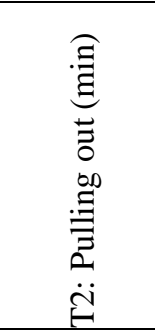 & 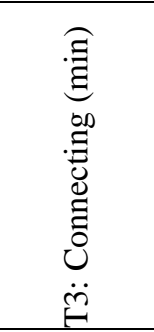 & 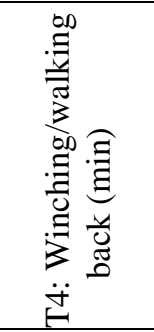 & 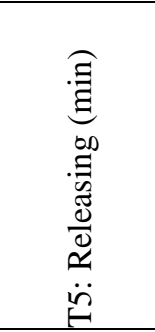 & 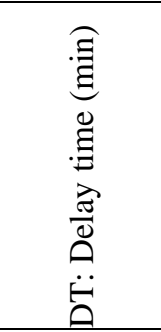 & 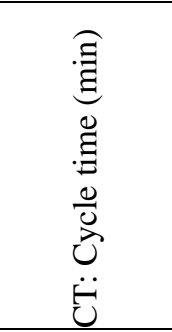 & 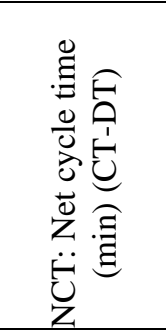 \\
\hline Average \pm SD & $0.77 \pm 0.57$ & $0.96 \pm 0.75$ & $0.18 \pm 0.10$ & $3.17 \pm 2.07$ & $0.15 \pm 0.04$ & $1.31 \pm 2.14$ & $6.39 \pm 3.39$ & $5.08 \pm 2.36$ \\
\hline Range (min-max) & $0.17-2.42$ & $0.18-3.28$ & $0.40-0.08$ & $0.48-9.47$ & $0.08-0.25$ & $0.00-9.70$ & $2.13-15.23$ & $1.45-11.22$ \\
\hline Percentages (\%) & 12.0 & 14.3 & 2.4 & 49.2 & 2.2 & 20.1 & 100 & \\
\hline
\end{tabular}

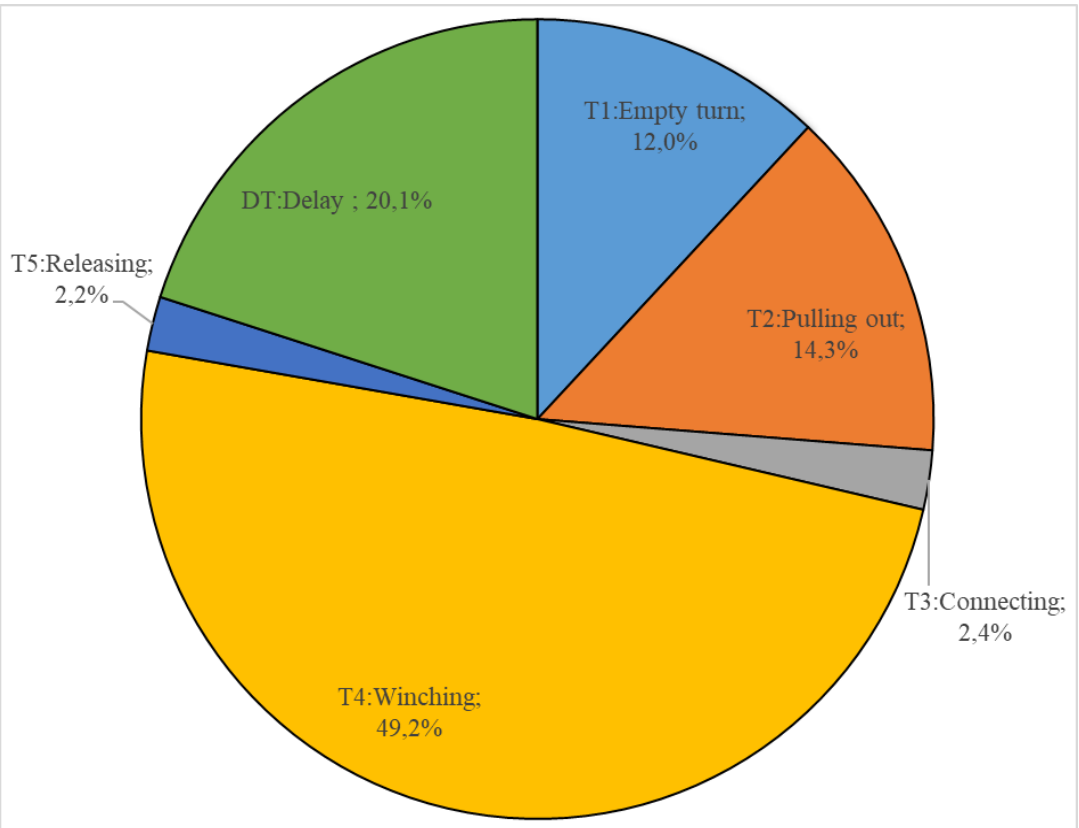

Figure 4. The average time consumption rate of work elements in a cycle during the winching operations 
Table 4. Average cycle time and productivity values of winching by the farm tractor

\begin{tabular}{llc}
\hline & Units & Values \\
\hline Cycle time & min.cycle $^{-1}$ & 6.39 \\
Productivity & $\mathrm{m}^{3} \cdot$ cycle $^{-1}$ & 0.62 \\
& $\mathrm{~m}^{3} \cdot$ hour $^{-1}$ & 5.80 \\
& $\mathrm{~m}^{3} \cdot$ day $^{-1}$ (for 8 hours) & 46.42 \\
\hline
\end{tabular}

\subsection{Cycle Time Predicting Model}

Some of the independent variables were highly changeable during the winching operations and they have significant effects on the work time and the productivity of the farm tractor. The independent variables considered in this study were: the winching distance (WD) and the diameter (d), the length (L) and volume $(\mathrm{V})$ of the extracted tree-length products. The two-tailed Pearson correlation analysis was conducted to determine the direction and intensity level of the relationship between the dependent and independent variables and to build a net cycle time (NCT) prediction model. Since the delay times were observed only in 24 work cycles, delay time values were excluded from the cycle time for calculation of the net cycle time (NCT). The results of correlation coefficient among variables for the winching time of the farm tractor are shown in Table 5.

Table 5. Correlation coefficients between dependent and independent variables $(n=35)$

\begin{tabular}{lcccc}
\hline \multirow{2}{*}{ Dependent variables } & \multicolumn{4}{c}{ Independent variables } \\
& Distance (WD) & Diameter (d) & Length (L) & Volume (V) \\
\hline T1: Preparation/empty turn & 0.096 & $0.378^{*}$ & -0.052 & $0.364^{*}$ \\
T2: Pulling out the cable & 0.161 & $0.473^{* *}$ & -0.156 & $0.371^{*}$ \\
T3: Connecting cable to load & $-0.335^{*}$ & -0.123 & $-0.442^{* *}$ & $-0.359^{*}$ \\
T4: Winching/walking back & $0.863^{* *}$ & 0.099 & 0.120 & 0.193 \\
T5: Releasing the cable & -0.161 & 0.156 & -0.294 & -0.024 \\
NCT: Net Cycle time & $0.817^{* *}$ & 0.324 & 0.024 & $0.361^{*}$ \\
Note: $* *$ Correlation is significant at the 0.01 level,*Correlation is significant at the 0.05 level \\
\hline
\end{tabular}

There was a positive correlation between the net cycle time and the winching distance $(\mathrm{r}=0.817)$ and the volume $(\mathrm{r}=0.361)$ at the 0.01 and 0.05 significant level, respectively. When the dependent work element times were considered in a cycle, there was a negative correlation between the connecting time (T3) and both the length and volume of the products at the 0.01 and at the 0.05 significant level, respectively. There was a positive correlation between the winching time (T4) and the distance at the 0.01 significant level while the volume positive but not significant at the 0.05 level.

Multiple regression analysis was conducted to estimate the significance of any relationship between the winching cycle times and the independents variables (Magagnotti et al., 2016). The step-wise regression method was preferred to show the effectiveness of the independent variables on the dependent (Özdamar, 2002) net cycle time (NCT) for the winching operations. Regression analysis showed that net cycle time was significantly affected by the winching distance (WD) while the other independent variables were not significant. The same result was determined by (Magagnotti et al. (2016) for two treatment of winching operation. In the regression model, independent variable winching distance (WD) explains $67 \%$ of the Net Cycle Time (NCT) with its standard error (1.398) of estimation (Table 6). This model was offered at $99 \%$ significant level $(\mathrm{p}<0.001)$.

Net Cycle Time $(N C T)=0.466+0.124 x W D$

During the winching operation by means of farm tractor, the longer winching distances can reduce the productivity due to increased winching times. In addition to these the another independent factors which significantly effective on productivity was extracted volume per cycle. The more volume winched in a cycle can increase the productivity of the machine (Figure 5).

Table 6. Regression model parameters for winching operation by means of farm tractor

\begin{tabular}{lcccc}
\hline \multicolumn{4}{l}{ Parameter Coefficients } & \multicolumn{3}{c}{ Standard error $t$-Value } & $p$-Value \\
\hline $\mathrm{a}$ & 0.466 & 0.614 & 0.759 & $<0.453$ \\
$\mathrm{~b}$ & 0.124 & 0.015 & 8.146 & $<0.001$ \\
$\mathrm{n}=35$ & $\mathrm{R}^{2}=0.668$ & $\mathrm{SE}=1.398 f$-Value $=66.365$ \\
\hline
\end{tabular}



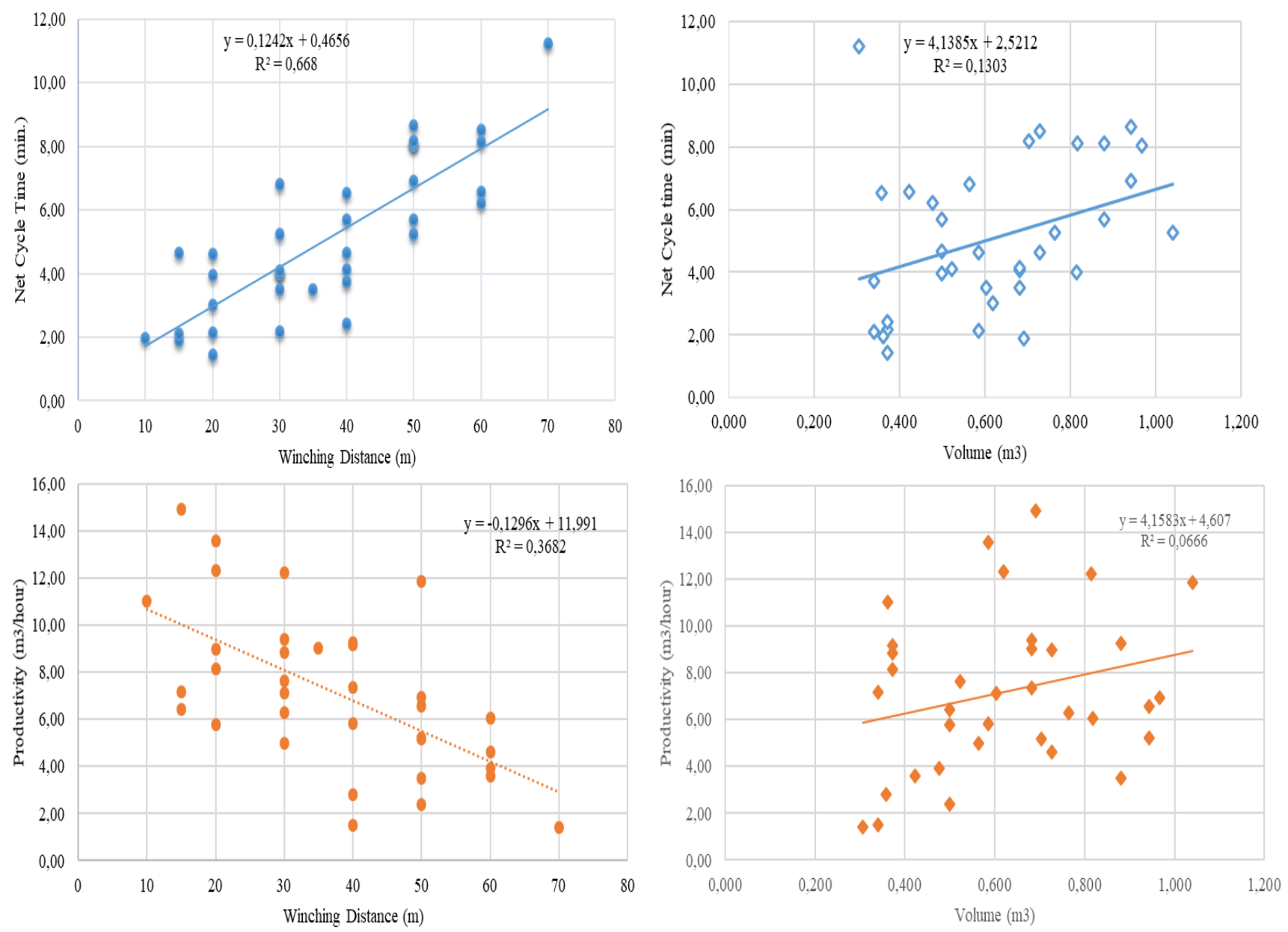

Figure 5. Relationship between dependent and independent variables

\section{Discussions}

Under the condition of the study, the tree-length harvested products were extracted uphill by using farm tractor and cable was pulled downhill by a worker in this present study. Akay (2005) pointed out that using farm tractor in small-scale forestry has several key advantages such as low investment and operating cost, versatility, and less damage on residual trees and soil. On the other hand, farm tractor can be limited by some factors including the terrain conditions, ground slope, and timber size. Some of the previous studies have already highlighted the negative impact of ground slope on the winching operations (Spinelli et al., 2014).

Berendt et al. (2020) determined the average pull-out time of the cable (downhill) by the worker and winching time was determined as $0.48 \mathrm{~min}$ and $1.22 \mathrm{~min}$, respectively, for the $50 \mathrm{~m}$ distance in a work cycle. The average work cycle time was determined as $2.03 \mathrm{~min}$ for the uphill winching direction on $25 \%$ sloped corridors by using mini forest crawler Wicki 50.6B. The winching time rate was $60 \%$ in a work cycle time. Gülci (2020) emphasized that the most time consuming work stage was the winching tree with $49 \%$ consumption rate and followed by pull-out time rope to the load (23\%) in a cycle. In this present study, the time consumption rate of winching $(49.2 \%)$ in a cycle was similar to the rates presented by Gülci (2020) while less than that of reported by Berendt et al. (2020). However, the winching time had still the highest rates in a cycle in both studies. The delay time was the second time consuming work elements in our study. Koutsianitis and Tsioras (2017) determined the work cycle time as $38.3 \mathrm{~min}$ for the tree-length skidding operations by using Unimog 406 skidders. They reported that the delay time rate was $6 \%$, which was 3.35 times less than that of founded in the present study.

In the present study, the productivity was calculated as $5.80 \mathrm{~m}^{3} /$ hour including times in a work cycle during the extraction of the tree-length products. Öztürk (2010b) found that the productivity of New Holland farm tractor (85 HP) for skidding distance of 140 and $320 \mathrm{~m}$. was 11.350 and $7.700 \mathrm{~m}^{3} /$ hour, respectively in beech stands. Gülci (2020) indicated that the productivity of uphill winching in a whole-tree system was 12.98 $\mathrm{m}^{3} /$ hour by using the single-drum winch equipped on the front of the farm tractor (75 HP). In both previous studies, the productivities were higher than the one found in the present study. This may be due to having a more powerful engine ( 75 and $85 \mathrm{HP}$ ) in previous studies than the tractor used in the present study (65 HP).

Gülci et al., (2018) found that the average productivity of the farm tractor for $20 \%$ and $30 \%$ ground slope classes were $5.72 \mathrm{~m}^{3} /$ hour and $4.30 \mathrm{~m}^{3} /$ hour, respectively. It was emphasized that the most time 
consuming work stage was skidding followed by moveout unloaded and choker setting stages. Considering their average productivity, results were very similar to the present study. Çağlar (2016) investigated the extraction of the spruce and Scots pine logs by the MB Trac 900 tractor under the conditions of $47.14 \mathrm{~m}$ skidding distances, 55\% ground slope where the ground was intensively covered by rhododendron. The average work cycle time was determined as 12.84 minutes. The rate of the pull-out cable and the winching times were determined as $13.6 \%$ and $44.2 \%$, respectively. These values were similar to the results found in the present study. In the present study, the rate of the pull-out cable and the winching times were also similar to the results reported by Çağlar (2016).

Both regression and correlation analysis showed that the net cycle time was significantly affected by the independent variables including winching distance (WD) and volume of extracted tree-length products. Magagnotti et al. (2016) emphasized that cycle times were significantly affected by the winching distance for two treatment of winching operation. The result of the present study was similar to their results. In another study conducted by Turk and Gümüş (2010) on logs skidding operation with farm tractors on skid trails, the regression analysis showed that the skidding time was significantly affected by skidding distance, condition of ground, slope of skidding trails.

Most of regression models for predicting skidding/winching time/or productivity indicate that skidding distance, piece size, load volume, winching distance and slope of the skid trail result in considerable impacts on the productivity of skidding operations (Abeli, 1996; Zecic et al., 2005; Öztürk, 2010b; Ghaffariyan, 2020). In particular, winching productivity is closely related to extraction distance (Spinelli et al., 2014) which means that longer winching distances can significantly reduce the productivity.

\section{Conclusions}

In this study, the productivity of uphill winching using a farm tractor during tree length harvesting operation was determined and the cycle time prediction model was developed using the multiple regression method. The results indicated that the average productivity was $5.80 \mathrm{~m}^{3} /$ hour which suits with the productivity estimations of similar studies. The most time consuming work element was found to be winching stage $(49.2 \%)$. It was found that delay time was the second most time consuming stage $(20.1 \%)$ in tractor winching operation. To decrease both winching and the delay time during the logging operation, the previous extraction lines (skid trail) must be used and the obstacles (such as stumps, logging residues, ground covers and stone, etc.) on the skid trails and winching corridors must be removed before the winching operations. In addition, the skidding trial need to be carefully planned and applied to the forest ground. In order to improve the productivity, the machine maintenance must be done on time, and spare parts should be available near to harvesting area.

Work safety, environmental protection and work efficiency should be taken as a priority during the extraction operation by using farm tractors. In the future studies, in addition to the independent variables related to the working environment, the experience and skills of the operators should be considered in productivity analysis for the harvesting operations. In this present study, the limited independent variables were measured and evaluated using the statistical analysis. To conduct more accurate prediction studies, similar methodology with more decision variables should be conducted in different harvesting areas where the farm tractors are used for timber extraction.

\section{Ethics Committee Approval: N/A.}

Peer-review: Externally peer-reviewed.

Conflict of Interest: The authors have no conflicts of interest to declare.

Financial Disclosure: The authors declared that this study has received no financial support

Cite this paper as: Çağlar, S., 2020. Productivity Analysis of Tree-Length Harvesting using Farm Tractor in a Nordmann Fir Stand in Turkey. European Journal of Forest Engineering, 6(2): 78-86.

\section{References}

Abeli, W., 1996. Comparing productivity and costs of three subgrading machines. International Journal of Forest Engineering, 5(1):33-39.

Akay, A., 2005. Using Farm Tractors in Small-Scale Forest Harvesting Operations, Journal of Applied Sciences Research, 1(2): 196-199.

Aykut, T., 1985. Mechanization and its productivity in transportation of forest products, In: Proceedings of The Conference on I. National Symposium of Mechanization and its efficiency in Forestry. 8-12 July, Bolu, Turkey.

Berendt F, Hoffmann S, Jaeger D, Prettin S, Schweier J., 2020. Application of spiroergometry to determine work metabolism related strain in the course of cable work with a mini forestry crawler. International Journal of Forest Engineering, 31(2):114-125.

Çağlar, S., 2016. Productivity of the MB Trac 900 tractor at the mixed conifer stands: an example of Artvin forest in Turkey, In: Proceedings of The Conference on International Forestry Symposium (IFS 2016). 0710 December, Kastamonu/Turkey.

Eker, M., Çoban, H. O., ve Acar, H. H., 2011. Time study and productivity analysis of chainsaw mounted log debarker in southern pine forests of Turkey. African Journal of Agricultural Research, 6(10): 2146-2156. 
Ghaffariyan, M. R., 2020. General productivity predicting model for skidder working in eucalypt plantations. Eur J Forest Eng, 6(1): 1-6.

Gülci, N., Akay, A.E., Erdaş, O., 2017. Productivity assessment of alternative timber debarking methods, Šumarski list, 9-10 (2017): 469-476.

Gülci, S., Büyüksakallı, H., Taş, İ., Akay, A. E., 2018. Productivity analysis of timber skidding operation with farm tractor. Eur J Forest Eng, 4(1): 26-32.

Gülci, S., 2020. Productivity of a farm tractor with single drum winch during whole-tree timber extraction, Šumarski list 1-2 (2020): 35-43.

Gullberg, T., 1995. Evaluating Operator machine interactions in comparative time studies. J. For. Eng. 7(1): 51-61.

Karaman A., 1997. Determination the effect of working difficulties on the production and the study on these factors relating the logging operations on the working conditions in Eastern Black Sea Forest Region [PhD dissertation]. Karadeniz Technical University, Trabzon, Turkey.

Koutsianitis, D., Tsioras, P., 2017. Time consumption and production costs of two small-scale wood harvesting systems in Northern Greece, Small-scale Forestry, 16:19-35.

Magagnotti, N., Aalmo, G. O., Brown, M., Spinelli, R., 2016. A New Device for Reducing Winching Cost and Worker Effort in Steep Terrain Operations,
Scandinavian Journal of Forest Research, 31(6): 602-610.

Özdamar, K., 2002. Statistical data analysis with package programs-1. (in Turkish), Kaan Publication, ISBN:975-6787-00-7, Eskişehir, Turkey.

Öztürk, T., 2010a. Productivity of MB Trac 900 tractor at beech stands on mountainous areas in blacksea region. African Journal of Agricultural Research, 5(1): 28-33.

Öztürk T., 2010b. Productivity of New Holland farm tractor at beech stands on mountainous areas in black sea region. Forestry Ideas, 16(1): 52-57.

Pulkki, R., 2019. Cut-to-length, tree-length or full tree harvesting? http://flash.lakeheadu.ca/ repulkki/ctl_ft.html, (Accessed: 15 May 2020).

Spinelli, R., Ottaviani Aalmo, G., Magagnotti, N., 2014. The effect of a slack-pulling device in reducing operator physiological workload during log winching operations. Ergonomics, 58(5):781-790.

Türk, Y., and Gümüș S., 2010. Log skidding with farm tractors, In: Proceedings of the FORMEC 2010, Forest Engineering: Meeting the Needs of the Society and the Environment. July 11 - 14, Padova, Italy.

Zecic, Z., Krpan, A.B.P., Vukusic, S., 2005. Productivity of $\mathrm{C}$ Holder $870 \mathrm{~F}$ tractor with double drum winch Igland 4002 in thinning beech stands. Croatian Journal of Forest Engineering, 26(2): 49-57. 